\title{
IVth Internationai Symposium on Neural Transplantation Transcript of the Closing Discussion (Edited)
}

\author{
(Session 44.0) \\ Washington, D.C.: July 16, 1992 \\ D. Eugene Redmond Jr. and Barry J. Hoffer (Co-Chairs) \\ and Discussants
}

\section{Eugene Redmond:}

I think that the sessions have been extremely interesting and provocative. It would be a shame to end the meeting without an opportunity to raise further questions, and to tie some issues together between the various sessions, such as relationships between the clinical and basic issues. There are many interesting loose ends, perhaps related to neural transplantation in general or to specific issues raised in the various sessions, that it would be useful to try to tie together. At the same time, because we have a large audience and hopefully many of you have important things to say, we are going to set some ground rules for the discussion that will give everybody an opportunity to speak. Therefore, we have chosen some specific topics as a way of beginning the discussion, and then we will open the discussion to the floor. We are going to ask the people who are speaking to limit themselves to 2 minutes so that everyone or nearly everyone can get an opportunity to speak.

The first issue in which several people have expressed a significant interest, is a continuation of the discussion concerning the design of clinical trials, and what do we need to do next to move the field forward. I have had a request from Patrick Aebischer to start that discussion.

\section{Patrick Aebischer:}

Several important questions have arisen during the course of today's interesting sessions. One of our major problems is the interpretation of clinical results. There are deficiencies in controls and ethical reasons prohibit the use of sham operations that might provide the best results. We may, however, be able to devise a system that would improve the current situation and would facilitate the comparison of results. I found it particularly disturbing that at the end of this afternoon I had to make up my mind on a very subjective basis, partly because all the groups used different techniques, different patient populations, varying ages of donors and different implant sites, and also utilized different surgical techniques and evaluations. Some groups also use cryopreservation. Under these circumstances, it is very difficult to draw any meaningful comparisons, especially when the number of patients is three or four. I therefore believe that there is a need to coordinate experiments to allow better evaluations and ultimately arrive at some clear conclusions. Regarding the problem of evaluation, I noted that at least one study made an attempt to use nonoperated patients as controls. Even if the numbers are small, it might be important to use this kind of study in a comparison, and to increase their number. Another important method was the use of blind evaluation. If I understand correctly, one or two groups tried to evaluate their patients "blindly", and this is certainly a very important and fundamental issue.

Finally, two small points. We have another neurosurgical alternative for the treatment of Parkinson's disease, that is, lesions. As you know, Mahlon Delong's work / $/ 2$ now suggests that it might be possible to lesion the subthalamic nucleus and obtain a striking improvement, at least in the MPTP monkey model. The neurosurgical community is considering trials of this procedure in human patients. Could clinical lesion trials of this type be compared to transplants in a rational fashion?

The people who presented it may be able to explain a little more clearly this last point. In the one patient that died there seemed to be no surviving cells. All PET scan data, however, suggest that there is survival of the transplanted 
cells. Has there perhaps been an improvement in the resolution or hardware of PET scans, so that we could be misled just by an improvement in the technology?

\section{Barry Hoffer:}

Would someone like to comment on any or all of Dr. Aebischer's questions?

\section{Curt Freed:}

We are not exactly starting from a blank piece of paper here. The results of experiments in rats and the related experiments in the monkey have been quite strong. Experiments in rats that have included controls suggest that dopamine cell transplants produce effects better than adrenal cells, at least without nerve growth factor. The fetal age of rat cells suitable for transplantation is a very narrow and well-defined stage of development. These results from animals have been at the heart of the planning process that we have used. The group from Lund has proceeded in the same way, although I don't want to speak for someone else. Our conclusions have also been supported by monkey experiments. We are using PET scans prior to surgery to demonstrate that the caudate is in relatively good shape and the putamen has a severe fluorodopa uptake defect. Based on the studies by Kish, Hornykiewicz and coworkers /10/, who have measured dopamine depletion in Parkinson patients, it looks like the putamen is the best target for transplantation. Targets can be individually chosen for each patient by using PET scans; in other words if fluorodopa uptake looks normal in the caudate, this would indicate that it is not necessary to use that as a target for transplantation. While the sprouting phenomenon observed after large lesions of the caudate is interesting, no one has provided evidence that sprouting occurs in the putamen after stereotaxic implants. Thus, the fluorodopa uptake data most likely show growth of fibers from the fetal dopamine cells. We would argue that experiments that are not using 6-8 week gestation human embryos, and which are not putting the tissue in the putamen are not going to be successful.

\section{Patrick Aebischer:}

It would be irrational to claim that rats and primates do not yield good data. The animal data do not, however, prove the validity of the human results. The problem arises when you have to scale up to humans. You are then dealing with a much larger structure. I think that it is important to design these studies so that they can stand on their own. It is difficult for those of us not doing clinical trials to draw any conclusions. To put it bluntly, should you not coordinate your clinical trials, so that you are no longer looking at 20 variables but less variables which are better controlled?

\section{Don Gash:}

My question follows up on Dr. Aebischer's comments. How far along are the groups doing clinical studies in terms of adopting a uniform set of standards? As I recall, in the transplant meeting that was held in Lund several years ago, a committee was formed to set standards for evaluating patients. These standards have been published $/ 11,12 /$. Are the groups doing clinical transplants following those standards?

\section{Olle Lindvall:}

The Core Assessment Program for Intracerebral Transplantation, that is, the "CAPIT", has been published in a book from the Lund meeting $/ 9,11 /$ and in Movement Disorders /12/. Several groups are now following CAPIT. In Europe we have organized a Network for Intracerebral Transplantation and Restoration called "NECTAR". A major task for NECTAR is to coordinate clinical trials with neural grafting in Europe. All groups in NECTAR will use CAPIT for evaluating their patients before and after transplantation.

One point that Dr. Aebischer brought up was related to PET scans. We have experience over several years with PET scans using the same machine in exactly the same way. We have definitely not seen improvement of fluorodopa uptake in all patients, and we have not seen improvement in all parts of the striatum. 


\section{Ignacio Madrazo:}

In relation to the clinical effect caused by the lesion, we have the experience of having used different kinds of grafts; so we have patients that have received fetal transplants, co-transplants, and adrenal transplants. The time course of evolution for every group of patients is completely different. So, we can clearly state that the clinical response is related to the grafts, because they have a completely different course of clinical evolution in the different kinds of grafts.

Scientists are calling on the clinicians to get organized. I will also call on scientists to get organized, because I have heard a lot of differences in the results of different groups in different labs. That's something that happens in science at all levels, so I think that it can also happen in clinics.

\section{Patrick Aebischer:}

Should we compare transplant studies to lesion studies, especially those following Mahlon Delong's studies /2/? I know that several groups have started to lesion the globus pallidus internal (GPI), and are thinking about lesioning the subthalamic nucleus. Could we not compare these procedures in clinical trials?

\section{Edward Hitchcock:}

Those interested in the lesion trials will almost certainly use the CAPIT scheme, so there will be a regularity and uniformity of approach, in which case the lesions can be compared to transplantation studies. As long as we all do the same assessments, it will be all right - it does not have to be the same group doing it which is the whole point of the CAPIT scheme.

\section{Olle Lindvall:}

It is important to state that, even if from the neurobiologist's point of view it is extremely exciting that we can restore neuronal circuits in the brain, the main clinical question regarding neural transplantation is whether and how much the patients get better. If you treat patients, it is your responsibility to test and compare different new possible approaches in a similar way. In my opinion the lesion data are clearly interesting, though this strategy has not been conclusively shown to be clinically valuable.

\section{Juan J. Lopez-Lozano:}

To me the crucial point at this time in the field of neural transplantation is, after searching among the audience, I have the feeling that we are losing our audience among neurologists. I think it is secondary to the way that we have conducted neurotransplantation and clinical studies. The problem of the lack of credibility of the results obtained in humans lies in several important factors, particularly as mentioned before. I think the situation of neurotransplantation in Parkinson's disease from the neurologic point of view is filled with serious difficulties. People from different countries have been using different techniques, different donor tissues, in different types of Parkinson's patients. All of these differences occur because of the lack of using common protocols or follow-up.

So, all of us are speaking our own language but nevertheless we are all getting good results. I can not understand why, using different kinds of tissues, in different people and using different follow-ups - let us say using adrenal medulla or fetal mesencephalon - we are getting such similar results. There are also puzzling differences in the time course of the clinical changes. I notice that some people using fetal ventral mesencephalon are getting good results two months after surgery, and for other groups the changes require 24 months. Using adrenal medulla, improvement sometimes lasts for two months and in other cases lasts 40 months. I would like somebody to explain to me how this can be possible.

\section{Patrick Aebischer:}

To be the Devil's advocate, I would like to draw your attention to the small improvements that are observed with the various procedures and tissue types used. I would then be worried about something called the placebo effect. 


\section{Don Gash:}

There is also the possibility of common mechanisms underlying recovery, if people are seeing very similar effects. Now, from this symposium, I am wondering if we could have some comments on the differences in the degree of recovery seen using adrenal medulla versus substantia nigra grafts. The other day, there were several groups who described results of co-graft trials. If Ray Watts is here, perhaps he could talk about using the co-graft approach and how promising those results have been. While a placebo effect is one possibility, those are other alternatives which are best studied in non-human primate models. Trophic factors stimulating residual host dopaminergic pathways, for example, might provide for a common mechanism underlying functional recovery in both adrenal medulla and fetal tissue graft recipients.

\section{Roy Bakay:}

I think that there is a feeling among many of us not directly involved with clinical fetal grafting investigations that we are unsure of the degree of improvement in these studies. If you look at the reports from everyone who presented today, from the first patient to the last patient, there has been a remarkable evolution. None of the investigators is still using the same techniques as on the first patient. The investigators are changing things, moving things around, and in each case they are doing something different. We must recognize this as an evolving process, and there is not a "technique" that can be applied on a large scale. One way to look at this question is to ask how many of us out here would ask one of these investigators to operate on our mother if she had a severe case of Parkinson's disease. I am not sure if there are a lot of people in the audience who are ready to make that decision before more studies are performed.

Ultimately a multicenter controlled study will be needed, but before that can be considered we have to develop a surgical technique that we can all agree is truly effective. The only way we can get to that point is to be able to compare the results of different groups in different countries using different techniques through use of the CAPIT protocol $/ 11,12,20 /$. Only by making the data complete, accurate, reliable and comparable can we compare results directly and not have to go through a series of indirect analyses. There is a big difference between a pharmacologic study and a surgical study. Surgical studies always go through this kind of evolution to refine a technique before implementing a randomized study or a controlled study. Even so, you can never randomize in the same way as a drug study. There are a lot of reasons for this, which I won't get into, but the reasons should be obvious.

\section{Curt Freed:}

Roy, at the same time I like the idea that we have the CAPIT set of standards, the fact that Parkinson's disease is variable means that there also has to be enough data on each individual patient to say that those measurements mean something in that particular patient. If you see a patient at isolated intervals, you get very little information, so you would have to say we need 50 CAPIT studies per patient, or something like that.

\section{Roy Bakay:}

The CAPIT standards deal with these issues of how many evaluations you need, how close together, and that sort of thing. Those factors must be considered in designing any study. The CAPIT recomendations are for the minimum requirements and the greater the number of pre-operative measures the better the assessment of the patient's severity and variability of symptoms.

\section{Tom Freeman:}

I think the critcisms that there should be more unification in methods is a little severe at this point. For a number of reasons, there are about 15 different variables that could influence the success of transplantation trials. It is healthy to try to approach this as each individual investigator sees fit, based on their own experience and their own laboratory data. It is premature to say that any one particular method is optimal, since no one has had an overwhelming success at curing all or even most 
symptoms of Parkinson's disease in the clinic, or in animals for that matter.

Another issue that $I$ think is being neglected is that there seem to be at least two different mechanisms that may be involved clinically, both of which may correct the symptoms of Parkinson's disease. In some cases, the graft may not have surviving dopaminergic neurons but may induce a trophic response in the host brain. It is also possible that clinical improvement may be obtained by having optimal survival of neurons that reinnervate the brain. I think that investigators should be clear as to which of these two strategies they are trying to optimize. Transplantation of fetal nigral tissue using techniques that do not produce surviving grafts in the laboratory, under the premise that it will create a neuronal hook-up of new circuits, is not particularly fair to the patients. If induction of trophic effects is the goal, there are several other types of tissues which are far safer, easier and more effective to use and may produce the same end result. Thus, we should attempt to assess beforehand what we are trying to achieve with our transplants.

\section{Barry Hoffer:}

Let's take one more comment on this topic and I guess Dr. Sladek, that means you are going to get the last word.

\section{John Sladek:}

I am glad Dr. Freeman raised that point because I think that we may be unduly harsh on ourselves, even though the objective of a scientist is to be self-critical. In fact, that is what research is all about, a great variation in design, approaches and techniques. Often usefully, and sometimes not so usefully, there are also differences in intrepretations but that is also what the purpose of this meeting is about. In the United States, our own government, in its infinite wisdom, chose not to fund this kind of research and I think that, had they chosen to do so, we might be sitting here after a 5 year coordinated clinical trial with more standardized approaches and more standardized interpretations. At the present level of knowledge, however, the lack of a coordinated clinical trial is not necessarily bad and I think the kind of selfanalyses and critical analyses we are having will clearly lead the field to a very positive endpoint.

I would add only one point of minor disagreement regarding reversing all the signs and symptoms in any of the patients. In addition to the fine studies that were presented today, I think the study by Dr. Widner and colleagues in MPTP patients $/ 21 /$ is probably the one that allows the clearest interpretation; after all, those are patients with a non-progressive form of parkinsonism. These MPTP patients more closely parallel the condition seen in the animal models that we have used, particularly the non-human primates. There we have seen several years of an exceptional level of improvement that is undoubtedly due to the survival of dopamine nerve cells from the grafted fetal neuroblasts. I hope we are not too hard on ourselves.

\section{Barry Hoffer:}

That is a good note on which to close the first part of the discussion. Let us now move on to a second topic that a number of people have talked about informally, and which may be appropriate for this round table. That is, we have focused on Parkinson's disease in particular and a few other diseases during the several days of this meeting, but what about other diseases? What kinds of diseases have we not discussed so far, or discussed only briefly, where transplantation of nerve cells might be of importance. Does anyone have any thoughts about that?

\section{Ignacio Madrazo:}

I don't have thoughts, I have cases. We have done already two cases of Huntington's disease. The first one is a patient now followed for more than one year after surgery and who has obtained a moderate benefit from surgery. She is still improving after one year. The second case was just done very recently. So, that is a new approach, and a different disease application of transplantation. 


\section{Olle Lindvall:}

There are a number of neurological disorders where there could be a potential usefulness of the neurografting techniques. From the clinical point of view, it is of course a dilemma for the doctor because, in many of these disorders, we have no treatment at all, and the symptoms are very severe. Nevertheless, in most of these disorders, there is no scientific basis for clinical trials even in desperate cases. In my opinion, the only disorder besides Parkinson's disease where presently one could motivate clinical trials is Huntington's disease. Huntington's disease is a fatal disorder, with progressive dementia. The patients die within 10 to 15 years, and there is no treatment. The lack of adverse effects in the Parkinsonian patients implanted with fetal dopamine cells, the evidence for growth, survival and function of the grafts in the human brain, as well as the importance of even a minor symptomatic improvement in Huntington's disease by neurografts would help to justify the first clinical studies with implantation of fetal striatal neurons into the striatum in Huntington's disease. However, in contrast to Dr. Madrazo, I don't think that we are at the stage yet when such studies should be initiated. There are a number of technical and scientific problems that we must solve before we can start even the first clinical trials in Huntington's disease. The animal experimental data are very promising: there is good evidence that striatal grafts can survive in the ibotenic acid-lesioned striatum, that they are at least partly anatomically and functionally integrated into the host neuronal circuitries, and that these grafts can improve cognitive and motor deficits. However, we know very little about how much tissue we should implant, what is the optimal donor age, and other technical aspects of critical importance for a clinical application.

There is also a major drawback at present in that we don't know how we shall assess cognitive and motor function in the Huntington's patients before and after transplantation. Furthermore, it is critical that we have methods to assess graft survival in these patients. When these problems have been solved, I think that we can justify clinical trials with neural grafting in a few patients with Huntington's disease.

\section{William Freed:}

Apparently, Jackie Sagen is not here, but she might want to say something about her data. The clinical trials in patients with chronic pain that she has described /17/ are extremely interesting and I think that continued work along these lines is certainly justified.

Aside from actual clinical trials per se, another issue that might be worthwhile to discuss is what other diseases potentially could provide applications for transplantation in the future. One of the diseases for which a very good case could be made, it seems to me, is epilepsy. In the case of epilepsy, I am not suggesting in any sense that clinical trials should be done now. However, it seems to me that this is a good possibility for the future. The abnormality can be localized anatomically and it originates from small areas of the brain. One of the major obstacles in epilepsy may be that the animal models are not adequate or are not sufficiently similar to human epilepsy. Would anyone care to comment on that perhaps?

\section{Olle Lindvall:}

We have been working with transplantation in experimental epilepsy for 7 years and have good evidence that neural grafts can suppress epileptic phenomena in the brain $/ 1,13 /$. In our model system, we have used kindled seizures which resemble temporal lobe epilepsy in humans. We implant noradrenergic neurons and can suppress the development of seizures in the kindling model $/ 1,13 /$, which may suggest clinical applications. However, it has not yet been shown that grafts can have also an anticonvulsant effect on established seizures.

Also, we have only been able to show the antiepileptogenic effect if we first damage the intrinsic noradrenaline system. That is a problem, because there are several forms of human epilepsy, and it is not known if any of them is linked to a deficiency in the intrinsic noradrenaline system. Thus, it is unclear whether our transplantation data obtained so far have any clinical relevance. We are now looking at other types of cells as well, e.g. GABA producing ones. I would strongly argue 
against any clinical trials with grafting in epilepsy at the present stage.

\section{Roy Bakay:}

You have to look at the severity of the disease and the severity of the proposed treatment. More desperate diseases require more desperate attempts at treatment. For a glioblastoma patient who is going to die within a year, there is a tremendous amount that can be done experimentally because the risk of the procedure can be balanced by the risks of dying from the disease. For someone with a disease in which they are going to live 20 or 30 years, the risks of any investigative procedure must be low and the experimental data need to be very compelling before you enter into surgical trials.

I think there are really only two other diseases where grafting techniques might be applied to humans in the near future; one is the cancer pain that Jackie Sagen's group presented $/ 17 /$, and the other would be in Huntington's disease /cf. $6,9,14,19 /$. In both cases, the patients die in a relatively short period of time and we don't have adequate therapy. We must avoid the mistakes that were made early on in Parkinson's disease, where we grafted adrenal tissue into numerous patients and only later found that it generally didn't survive and only worked for a short period of time. For diseases that run a benign course we need to do a great deal of animal investigation, exactly as Dr. Lindvall was describing earlier. I think that there is absolutely no reason to start clinical trials for the other diseases discussed today such as epilepsy. It is important to remember that the animal models are not the disease. We need to understand the pathophysiology of these diseases and the mechanism of graft function before applying this technology to "benign diseases".

\section{Richard Bunge:}

If we are to develop a catalog of potential transplantation applications in neuronal loss diseases, I think it should be mentioned that, at this meeting, there have been a number of rather remarkable papers about the success of replacing lost somatic motor neurons in the spinal cord. One approach has involved introducing fetal tissue into regions of the spinal cord depleted of its normal motor neuron population. In work from France from Drs. Horvat and Peschanski $/ 8,15 /$, these implanted motor neurons have been successfully guided to nearby muscle by nerve bridges. This work provides evidence that transplanted motor neurons in spinal cord in experimental animals, especially rats, can be guided to successfully innervate skeletal muscle. Another more extreme approach to this kind of injury, and to motor neuron disease in particular, is to actually place motor neurons in the peripheral nerve near a denervated muscle. The purpose in this case is to provide absent neuromuscular innervation with the hope of driving these isolated transplanted motor neurons by functional electrical stimulation to attain functionally useful contraction $/ 5 /$. In summary, I think there have been early but promising developments in the possibility of replacement of the somatic motor neuron.

\section{Helen Hodges:}

I think another case where it might be possible to develop transplants for human therapeutic use is after heart attack. There are animal models that mimic very exactly the interruption of blood flow to the brain and also result in focal hippocampal damage. This sort of damage has been identified in heart attack victims. In fact, about 20 percent of people who survive heart attacks are found to suffer from very severe memory deficits. I think what some clinicians could be doing at the moment is building up very accurate pictures of the kind of memory deficit and the type of cell loss that occurs following heart attack, so that animal models that mimic these same patterns of damage could be developed. We could thus look at the effects of transplanting particular cell types. For instance, we have found the CA1 cell type to be an important factor in improving memory performance of animals with CA1 cell loss following ischemia. I think that ischemia-induced injury is an area where clinicans could do a lot of preparatory work while animal models are being developed. 


\section{Barry Hoffer:}

Let us now move on to a final topic for general discussion that some people brought up informally over the last few days. We started to see glimmers of this around the time of the Third Intenational Meeting in Cambridge and a bit earlier, and it has really grown very impressively to maturity here. Perhaps not full maturity as yet, but adolescence certainly. This is the application of genetic engineering and immortalization techniques to cells that are to be transplanted. Perhaps we could now have some comments about that.

\section{Richard Robbins:}

There are a number of very important issues to consider when dealing with these kinds of approaches for cell transplantation. Obviously, one of the most important is that many of the genes that are introduced in order to help cells divide are in the category of oncogenes, and these can actually induce a condition of transformation. Such transformed cells may have anywhere from a small to a large capacity to continue to divide in the central nervous system. The development of, for instance, temperature-sensitive oncogenes such as those described by Ron McKay and co-workers at this meeting $/ 4 /$ is a significant advance in trying to overcome this problem. Another category of genes that don't normally induce a transformed phenotype, called immortalizing genes, have begun to be explored as a possible way to turn a switch on in a cell to make it divide. Such immortalized cells may continue to produce their own native factors or biologically active molecules. Genes such as the adenorviral E1A gene are an example. There are some new genes coming down the pike that might not have the transforming potential, and could potentially be useful for development of cell lines.

I think that one of the other general approaches that might need to be considered carefully here is whether or not we can simply transplant cells that have been modified to overproduce one growth factor or one neurotransmitter in an unregulated way, as opposed to implanting cells that have a neuronal phenotype and may be able to make appropriate synaptic connections and release either proteins or small neurotransmitters in a regulated way.

A major issue that one should consider when trying to create cell lines, is that there are two fundamentally different approaches. You can start with the cell that you want and add one gene that helps that cell divide, hopefully changing its phenotype as little as possible. Alternatively, you can take cells that can be genetically manipulated quite easily, and introduce the gene, for instance, for tyrosine hydroxylase, to try to get that cell to make dopamine. I think we are obviously going to have to demonstrate that any cell that makes a certain factor can be transplanted not only into rodents but primates with a great deal of safety before we will be able to approach our institutional review boards or human safety committees to convince them that we will be able to put these cells into a human and have absolutely no chance of forming a tumor.

\section{Paul Carvey:}

This a general observation. I see a lot of people doing very nifty things with gene transplantation it is a marvelous field. Nonetheless, I am always the individual who asks the question - how far does the substance diffuse? I see a lot of individuals who are trying to develop things that may not be practical because the substances they are trying to make don't diffuse far enough from what is essentially a point source. So I think that it is important that you should establish these fundamental principles before developing a protocol to engineer something. If you make it and implant it into the brain, can it diffuse far enough to do any good?

\section{Edward Baetge:}

The ultimate cells for neural transplantation may be those that can naturally give rise to specific differentiated phenotypes and be propagated continuously in culture. There are now a number of neuroepithelial progenitor cells which have been immortalized using SV40 or Myc retroviral transgenes as recently described by Ron McKay and co-workers $/ 4 /$ and Connie Cepco and coworkers $13 /$. Although these cells appear to 
differentiate after in vivo transplantation, it remains to be determined what true long-term in vivo potential they have and whether the immortalizing transgenes they express are safe for prolonged in vivo use. An alternative cell might have the properties of a neural stem cell, giving rise to both neurons and glia but also capable of continuous propagation in vitro without the use of immortalizing or transforming genes. As described earlier today, Sam Weiss and Brent Reynolds $/ 16,18$ / provided evidence for such a cell that was capable of being continuously grown in vitro and differentiated into a number of neuronal and glial cell types. Such cells are unmodified and might provide a plentiful transplantation cell source assuming they could maintain their potential for differentiation upon transplantation or treatment with various mitogenic or trophic factors. Much work remains to determine the full potential for the in vitro/vivo generation of differentiated CNS cell types, but for the first time we are able to continuously culture neuroprogenitor cells which should provide for rapid progress in this area.

\section{Fred Gage:}

Another way to look at the idea of gene transfer from the central nervous system is to take it out of the context, if we could for the moment, of the clinical setting. There are other reasons why one would want to introduce genes into the central nervous system. Traditionally, the approach we have had in these meetings has not been just to address diseases, but also to use transplantation as a methodology to understand something about the brain. In that context, I think the delivery of individual genes, either somatically through the use of transplanted cells or directly through direct gene delivery, is one way of more specifically asking questions about how specific proteins or transmitters function within the central nervous system. To that end, we are at the early stages of this methodology. There are at least 10 questions that have been raised just by the last two speakers and I can think of 100 more that are necessary to be addressed, not for any kind of clinical application but even in terms of utilizing this as a tool. But I would say that from what we have seen in this meeting in the last few days, there have been probably $15-20$ new applications of gene delivery in the central nervous system as a method of looking at regenerative responses and release of transmitters.

While there are a lot of questions that remain to be answered, I think that what we are seeing is the birth of a field which will help us to address more specifically the role that transmitters and trophic factors play in the central nervous system. If we think about it that way, rather than immediately trying to think about how we can apply this to a clinical setting, we might be able to resolve some of the fundamental issues first, such as what cell type to use, and ways of achieving long term regulatable gene expression, before we start designing things specifically for their clinical applications.

\section{Phillipe Horrellou:}

I would like to add some comments to the previous ones. As you know, genetic engineering for intracerebral transplantation is a new field. What we have achieved so far is the use of genetic tools to produce and deliver neurotransmitters or growth factors after gene transfer to cells for transplantation. In our efforts to compensate for degenerative processes, for the time being, we have at best been able to deliver the molecules though diffusion from the grafted cells. There are a number of tools and experimental conditions that are now being approached in order to improve these methods to obtain specific and regulated release from neurons, such as immortalized neuroepithelial cells developed, for instance, by Ron McKay /4/. Beside genetic modification of cells for transplantation, direct gene delivery into neurons is emerging with new vectors. Such vectors, for instance those illustrated by the methods which were very nicely described by Joseph Glorioso in this meeting $/ 7 /$, may soon be available. We are still at a starting point and very few applications of these vectors have been presented. However, we would like to remove the viral genes which are present in these vectors that might induce side effects. I think that there is a requirement for major improvements in the genetic engineering systems before we can go in a clinical direction. In conclusion, gene transfer to the brain is a starting 
field and major improvments are taking place. It requires considerable effort to develop these tools for clinical applications, both in term of efficiency and in terms of safety.

\section{Jens Zimmer}

If I may say a few words, I find it extremely fascinating in this meeting to see that cells that are normally in the brain can be taken out, immortalized, and then can actually be put back into the brain again by using transplantation as a tool. In the adult rat brain, within 15 days such cells can transform into genuine CA3 pyramidal cells if you put them in the hippocampus, neocortical pyramidal cells when you put them in the neocortex, or they can be granule cells when you put them in the cerebellum. With other cell lines, glial cells may be formed. I am really looking forward to the meeting in Paris, because I think that we are at a stage that we will soon see great advances and refinement in the techniques.

Going back to the clinical issue, I would say that in many of the cases where we do not know the mechanisms of a disease, we nonetheless see that certain nerve cell types degenerate. After cerebral ischemia, the CA1 pyramidal cells in the hippocampus are, in particular, susceptible. I think that in two years time in Paris, we may see cell lines that when introduced into the brain, into the CA1 area, will transform into CA1 pyramidal cells. Moreover, a very interesting thing is that the adult brain seems to have instructions, or environmental conditions, that will make these cells differentiate and perhaps even form - and this is where basic research comes in - the right connections. So, in that sense I am very optimistic about the prospects for this methodology. With refinements in techniques, and also with further clarification, we may see large advances in cell engineering and development. Many of these we may have predicted, but now in some cases we know for sure what is possible.

\section{Richard Robbins:}

I would just like to extend that thought by saying that I think that some of the newer molecular biological approaches for understanding the commitment of precursor cells in the brain and understanding how to express genes after the cells have made a terminal commitment are going to be very dramatic. In four or eight years time, when we have these meetings, we are not even going to be talking about transplanting fetal tissue anymore. Fetal tissue is going to become a thing of the past very soon and we are only going to be talking about transplanting engineered cells.

\section{Curt Freed:}

Dr. Robbins, this has not happened yet with kidneys, livers or hearts. I think we have to be humble when we look at the evolution of these wonderful dopamine cells. It will not be easy to make our own versions of normal brain cells.

\section{Barry Hoffer:}

Are there other topics or areas the audience would like to explore?

\section{Larry Kromer:}

I would just like to add a comment. At the end of these meetings we always look for clinical applications. Our discussion is usually focused on cell replacement theories and the clinical application of replacing degenerating neurons. I think that there is a whole aspect of transplantation that has a very classical history from early in the century, and that is to understand how the nervous system is put together, the intricate interactions between cells, and the role of glial cells in this interaction. I think that we should not lose our appreciation for using transplants to understand the nervous system and its development. We should not always have to feel it has to have clinical application as a primary focus.

\section{Barry Hoffer:}

Your point is very well taken. Do we have other comments?

\section{Paul Sanberg:}

I heard the comment earlier, that perhaps in about four or five years we won't even be 
transplanting fetal cells. One area we need to think about is how do you determine the "dose" of cells to transplant? Right now we are lucky, in that we are implanting autografts of adrenal cells, or allografts of fetal cells. Perhaps $10 \%$ of the mesencephalic cells that we are transplanting are dopaminergic. However, when we start using engineered cells, we will have very large numbers of pure dopamine- secreting cells, or growth factorsecreting cells. If we are successful, and we use these cells as a cell therapy, it is not like a drug. These cells are going to stay in there. Thus, we really need to think about how we dose these things. With any drug, for example, you get a certain percentage of patients that show abnormal responses. Some adverse responses and side effects can be anticipated with cell transplants as well. How do you take those cells out, how can you get rid of them if the patient has an abnormal adverse response? We have so far been quite lucky with most of the clinical data. With the fetal cell grafts, we have not seen many harmful effects, but I think as we get into these other types of cells, it's going to be a real critical issue and one to think about.

\section{Barry Hoffer:}

We would like to close this discussion by expressing our graditude to the organizers, the audience, and all of the participants for an enlightening and stimulating meeting. I think that everyone has done a wonderful job. There was a lot of effort involved in organizing this meeting, and we want to thank all of you very much for participating.

\section{REFERENCES}

1. Bengzon J, Kokaia $Z$, Kokaia $M$, Lindvall $O$. Functional specificity of locus coeruleus grafts in kindling epilepsy. Rest Neurol Neurosci 1992; 4: 215.

2. Bergman $H$, Wichmann $T$, DeLong MR. Reversal of experimental Parkinsonism by lesions of the subthalamic nucleus. Science 1990; 249: 1436-8.

3. Cepko C, Snyder EY, Deitcher DL, Walsh C, ArnoldAldea S, Hartweig EA. Multipotent neural cell lines can engraft and participate in development of mouse cerebellum. Rest Neurol Neurosci 1992; 4: 135.

4. Cunningham M, Vicario C, Arel L, McKay R. (McKay presenting). Multipotential stem cells for neurons and astrocytes in the vertebrate CNS. Rest Neurol Neurosci 1992; 4: 192.

5. Erb DE, Kim JH, Lee WH, Bunge RP. Reinnervation of adult skeletal muscle using embryonic spinal cord cells grafted into the axotomized tibial nerve. Soc Neurosci Abstr 1991; 17: 233.

6. Freed WJ. Neural transplantation: Prospects for clinical use. Cell Transplantation 1993; 2: 13-31.

7. Glorioso JC, Goins WF, Sternberg LR, Levine M, Fink DJ. Development of herpes simplex virus as a gene transfer vector for the nervous system. Rest Neurol Neurosci 1992; 4: 192.

8. Horvat J-C, Pecot-Dechavassine M, Baillet-Derbin C, Mira J-C, Ye JH, Rhrich F, Affane F. Transplantation strategies to reconstruct the injured spinal cord and its peripheral motor connections in the adult rat. Rest Neurol Neurosci 1992; 4: 182.

9. Isacson $O$, Hantraye $P$, Maziere M, Riche D. Crossspecies striatal neural implants reduce dyskinesias in a primate model of Huntington's disease. Rest Neurol Neurosci 1992; 4: 129.

10. Kish SJ, Shannak K, Hornykiewicz O. Uneven pattern of dopamine loss in the striatum of patients with idiopathic Parkinson's disease. N Engl J Med 1988; 318: 876-80.

11. Langston JW, Widner H, Brooks D, Fahn S, Freeman T, Goetz C, Watts R. Core assessment program for intracerebral transplantations (CAPIT). In: Lindvall O, Björklund $\mathrm{A}$, Widner $\mathrm{H}$, eds, Intracerebral Transplantation in Movement Disorders. Amsterdam: Elsevier 1991; 227-41.

12. Langston JW, WIdner H, Goetz CG, Brooks D, Fahn, S, Freeman T, Watts, R. Core assessment program for intracerebral transplantations (CAPIT). Movement Disorders 1992; 7: 2-13.

13. Lindvall O, Bengzon J, Brundin P, Kalen P, Kokaia M. Locus coeruleus grafts in hippocampal kindling epilepsy: Noradrenaline release, receptor specificity and influence on seizure development. In: Dunnett, SB, Richards S-J, eds, Neural Transplantation: From Molecular Basis to Clinical Applications. Amsterdam: Elsevier; Prog Brain Res 1990; 82: 339-46.

14. Norman AB, Sanberg PR. Fetal striatal grafts: Current status of behavioral studies. Rest Neurol Neurosci 1992; 4: 129.

15. Peschanski $M$, Nothias $F$, Cadusseau J. Is there a therapeutic potential for intraspinal transplantation of fetal spinal neurons in motoneuronal diseases? Rest Neurol Neurosci 1992; 4: 227.

16. Reynolds BA, Weiss S. A non-transformed, growth factor-dependent stem cell line derived from the embryonic mouse CNS produces neurons, astrocytes and oligodendrocytes. Rest Neurol Neurosci 1992; 4: 208.

17. Sagen J, Pappas GD. Alleviation of chronic pain by adrenal medullary transplants. Rest Neurol Neurosci 1992; 4: 229. 
18. Weiss S, Reynolds BA. EGF-responsive CNS stem cells persist in the embryo to the adult. Rest Neurol Neurosci 1992; 4: 228.

19. Wictorin K, Campbell K, Bjorklund A. Anatomical integration of intrastriatal striatal grafts with the adult host brain: Specificity and functional aspects. Rest Neurol Neurosci 1992; 4: 129.

20. Widner H, Langston JW, Brooks D, Fahn S, Freeman T, Goetz C, Watts R. CAPIT - Core Assessment
Program for intracerebral transplantation. Rest Neurol Neurosci 1992; 4: 223.

21. Widner H, Tetrud J, Rehncrona S, Snow B, Brundin $\mathbf{P}$, Gustavii B, Björklund A, Lindvall O, Langston JW. Bilateral fetal mesencephalic grafting in patients with severe MPTP-induced Parkinsonism: Results after 2 years. Rest Neurol Neurosci 1992; 4: 181. 

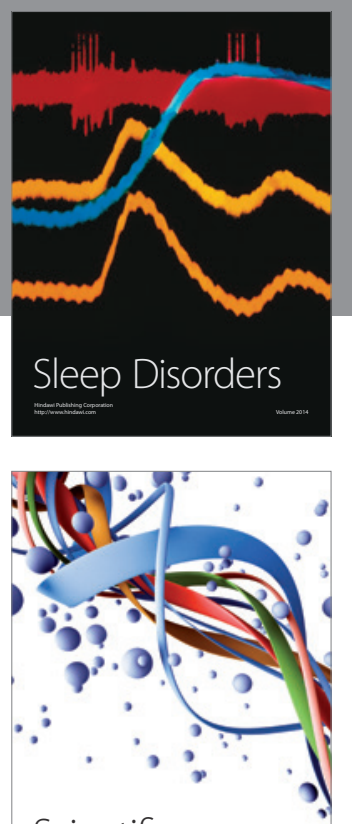

Scientifica
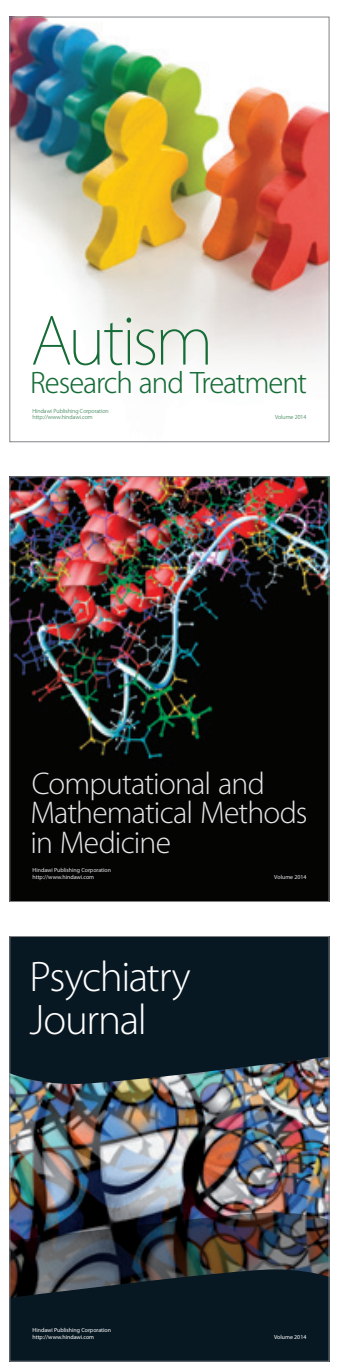
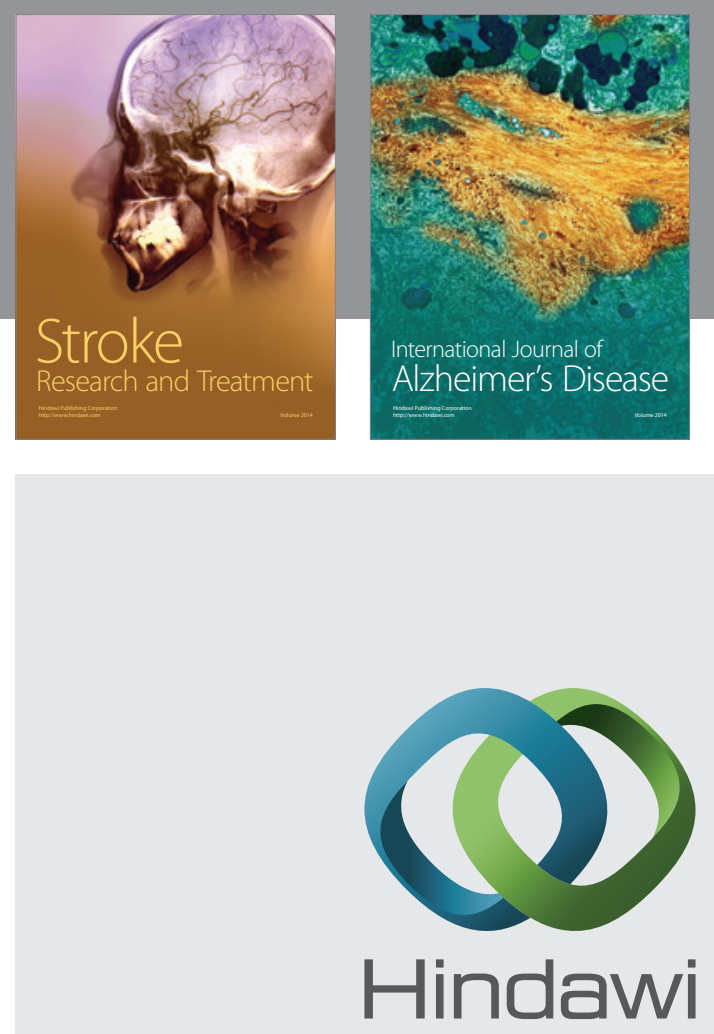

Submit your manuscripts at

http://www.hindawi.com
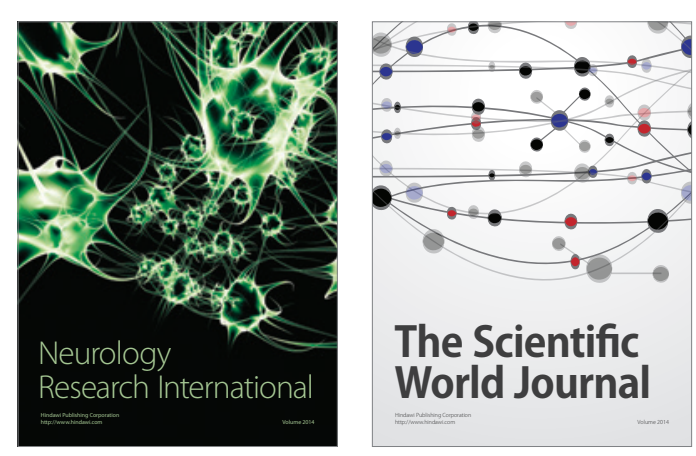

The Scientific World Journal

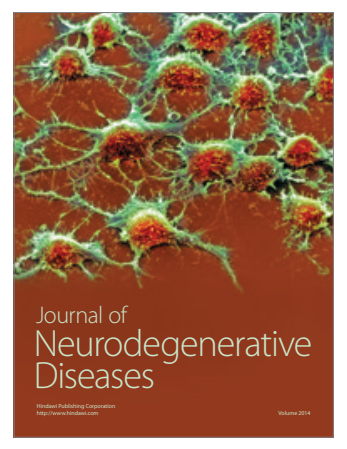

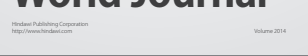

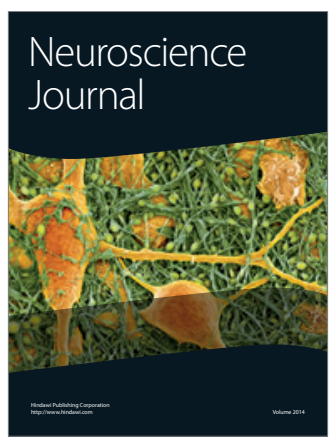

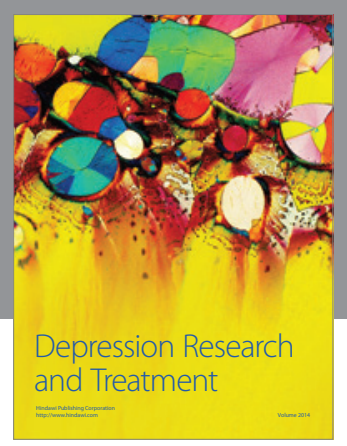
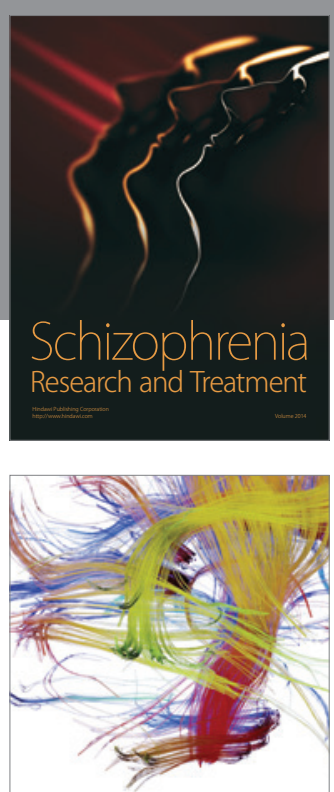

Brain Science

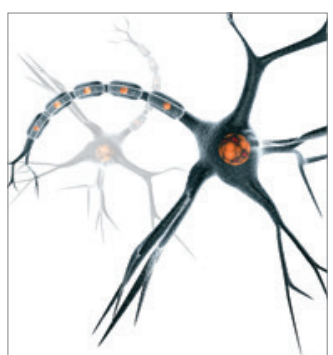

Neural Plasticity
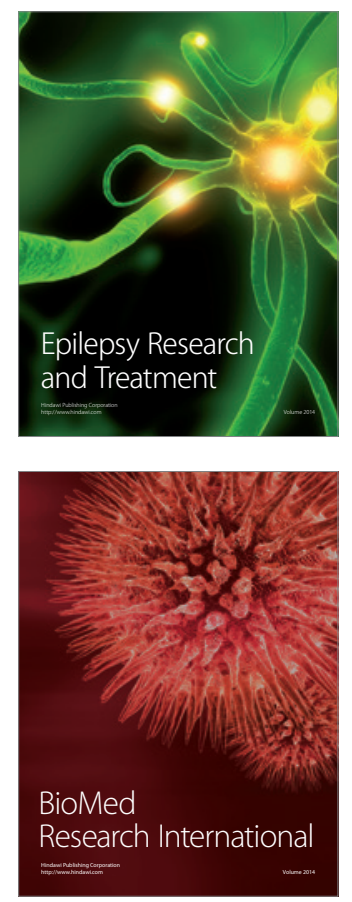

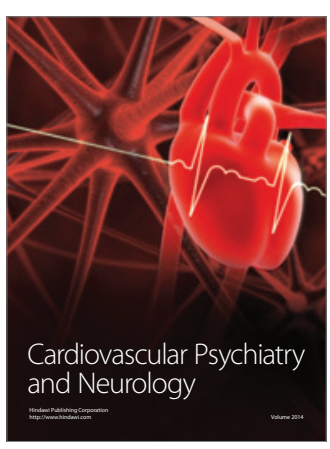

Parkinson's

Disease
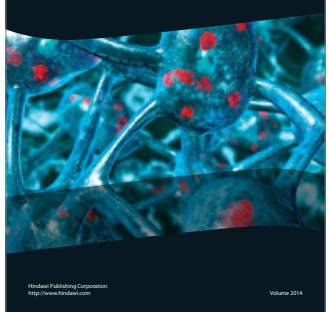